\title{
EVOLUÇÃO DA INFORMAÇÃO APOIADORA DA GESTÃO AMBIENTAL: UMA ANÁLISE CENTRADA EM SEUS ESTÁGIOS EVOLUTIVOS E NOS AGENTES DECISÓRIOS
}

\author{
Rosana Cristina Colombo Dionysio \\ Fernando César Almada Santos
}

\begin{abstract}
Resumo
Diante da questão ambiental fortemente explicitada, governo, empresas e a população em geral estão sendo convocados a refletir, tomar iniciativas e aplicar soluções em busca de uma diminuição ou prevenção dos problemas ambientais. Neste contexto, o presente artigo tem com objetivo identificar tipos de decisão, informações e agentes decisórios para a condução de uma administração das questões ambientais nas organizações, seja qual for o estágio de evolução ao qual a empresa se encontra. Dessa forma, foi realizada uma revisão bibliográfica que abrangeu os temas gestão da informação, gestão ambiental e estágios evolutivos da gestão ambiental. Foi possível observar que a quantidade e os tipos de informação que são necessários em cada um dos estágios da gestão ambiental são diferenciados, porém com ressalva em alguns tipos, que podem ser utilizados em mais de um estágio. Para tanto, se faz necessária uma gestão da informação de forma completa, considerando vários tipos e fontes de informação, para que estas possam auxiliar os dirigentes das organizações na formulação de estratégias e principalmente nas tomadas de decisão, adotando uma gestão ambiental pro ativa.
\end{abstract}

\author{
Palavras-Chave \\ Gestão da informação; Gestão ambiental; \\ Norma ISO 14001
}




\section{INTRODUÇÃO}

Diante das preocupações relacionadas à sustentabilidade, as empresas industriais vêm tomando providências para sua adequação num novo cenário organizacional. Esse novo cenário, além de turbulento e imprevisível, requer responsabilidades com o meio ambiente, fazendo com que as empresas desenvolvam novas formas de produção e desenvolvimento, além de proporcionar crescimento econômico ao país.

Dessa forma, o número de informações que norteiam essas mudanças é significativo e requer gerenciamento tão amplo quanto à própria complexidade dessas informações. Assim, o recurso informação já tem sido estudado e reconhecido como fator imprescindível às organizações. McGee e Prusak (1994) afirmam que a informação deve ser tratada como recurso estratégico e precisa ser administrada diariamente, com o mesmo cuidado e atenção dispensado aos recursos humanos e financeiros da organização.

Outra necessidade de mudanças internas identificada é a busca de novas informações, seja sobre os impactos ambientais de processos e produtos, atuais e futuros, seja sobre conceitos, ferramentas, técnicas, tecnologias e sistemas para capturar esses impactos ambientais, seja sobre as exigências e tendências externas. Ao mesmo tempo, é preciso acolher formas de pensamento e análise que comportem as ambigüidades, complexidades e interdependências dessas informações (SANCHES, 2000).

Diante deste contexto, o presente artigo contribui com o desenvolvimento de uma perspectiva teórica que relaciona a gestão da informação e a evolução ambiental das organizações. Assim, algumas questões se tornam pertinentes:

- Quais são as tomadas de decisão e as informações necessárias em cada estágio da evolução ambiental?

- Quais são os agentes decisórios envolvidos nessas tomadas de decisão?

Dessa forma, este artigo expõe uma relação entre a informação e a importância de sua gestão nos estágios de evolução das empresas com relação às questões ambientais.

\section{GESTÃO AMBIENTAL E AS ORGANI- ZAÇÕES}

O meio ambiente tem-se tornado um elemento vital para se estabelecer os novos paradigmas da concorrência industrial e, por isso, aflora como importante questão para se estabelecerem os rumos futuros dos mercados e da sociedade, locais ou globais (SANCHES, 2000). Dessa forma, as organizações têm se preocupado, de maneira acentuada, em incorporar a variá- 
vel ambiental na prospeç̧ão de seus cenários e na tomada de decisão, além de manter uma postura responsável de respeito à questão ambiental (DONAIRE, 1999).

Para tanto, a quantidade de variáveis que abrange as questões ambientais torna sua gestão tão complexa que se faz necessário definir o termo gestão ambiental.

Para Barbieri (2004), gestão ambiental é o conjunto de diretrizes e as atividades administrativas e operacionais, tais como planejamento, direção, controle, alocação de recursos e outras realizadas com o objetivo de obter efeitos positivos sobre o meio ambiente, quer reduzindo ou eliminando os danos ou problemas causados pelas ações humanas, quer evitando que eles surjam.

Porém, dependendo de como as empresas atuam em relação aos problemas ambientais, elas podem estar localizadas em fases diferentes de implementação de sua gestão ambiental. Algumas empresas, por exemplo, podem começar implementando sua gestão ambiental pela área de produção, que por sua natureza transformadora de recursos, é a de maior impacto ambiental e, portanto, aquela onde o envolvimento com a gestão ambiental é mais explícito (CORAZZA, 2003). Outras, porém, vêem a proteção ambiental como uma função da administração, pois contemplam planejamento estratégico, discus- são de cenários alternativos e a conseqüente análise de sua evolução, gerando políticas, metas e planos de ação (DONAIRE, 1994).

Dessa forma, para que a gestão ambiental seja incorporada por todas as atividades da organização, o departamento de gestão ambiental ou o responsável deverá estabelecer uma rede de contatos tanto no nível interno quanto no externo, principalmente no que tange à comunicação e transparência das informações. Em nível interno, seus contatos serão realizados com as demais unidades administrativas, discutindo informações sobre legislação ambiental, novas tecnologias, acompanhamento de melhorias, poluição, reciclagem, aproveitamento de resíduos, economia de energia etc. Em nível externo, representando a organização e traduzindo seus valores ambientais para o mundo exterior, deverá se envolver com os órgãos governamentais, comunidade, imprensa, organizações civis, associações ambientalistas, políticos, associações de classe, associações internacionais etc (DONAIRE, 1999, p. 87).

\section{GESTÃO DA INFORMAÇÃO}

\section{AMBIENTAL}

O gerenciamento da informação é, atualmente, tanto do ponto de vista acadêmico como de suas aplicações no mundo dos negócios, um assunto de grande 
relevância. Com relação à gestão ambiental, este discurso não poderia ser diferente. Empresas que estão em etapas de atendimento a conformidades ambientais ou mesmo que já implantaram sistemas de gestão ambiental (SGA), necessitam a todo o momento tomar decisões em relação às questões ambientais.

$\mathrm{Na}$ aplicação de sistemas de gestão ambiental, como a NBR ISO 14001, inúmeras decisões são tomadas. Estas decisões, por sua vez, envolvem um grande número de informações e a participação de muitas pessoas.

Uma empresa que implanta um sistema de gestão ambiental adquire uma visão estratégica em relação ao meio ambiente, pois deixa de agir em função apenas dos riscos e passa a perceber também as oportunidades (MOREIRA, 2001, p.52). Na Figura 1 está reproduzido o modelo de sistema de gestão ambiental proposto na norma ISO 14001, deixando claro o compromisso com a melhoria contínua.

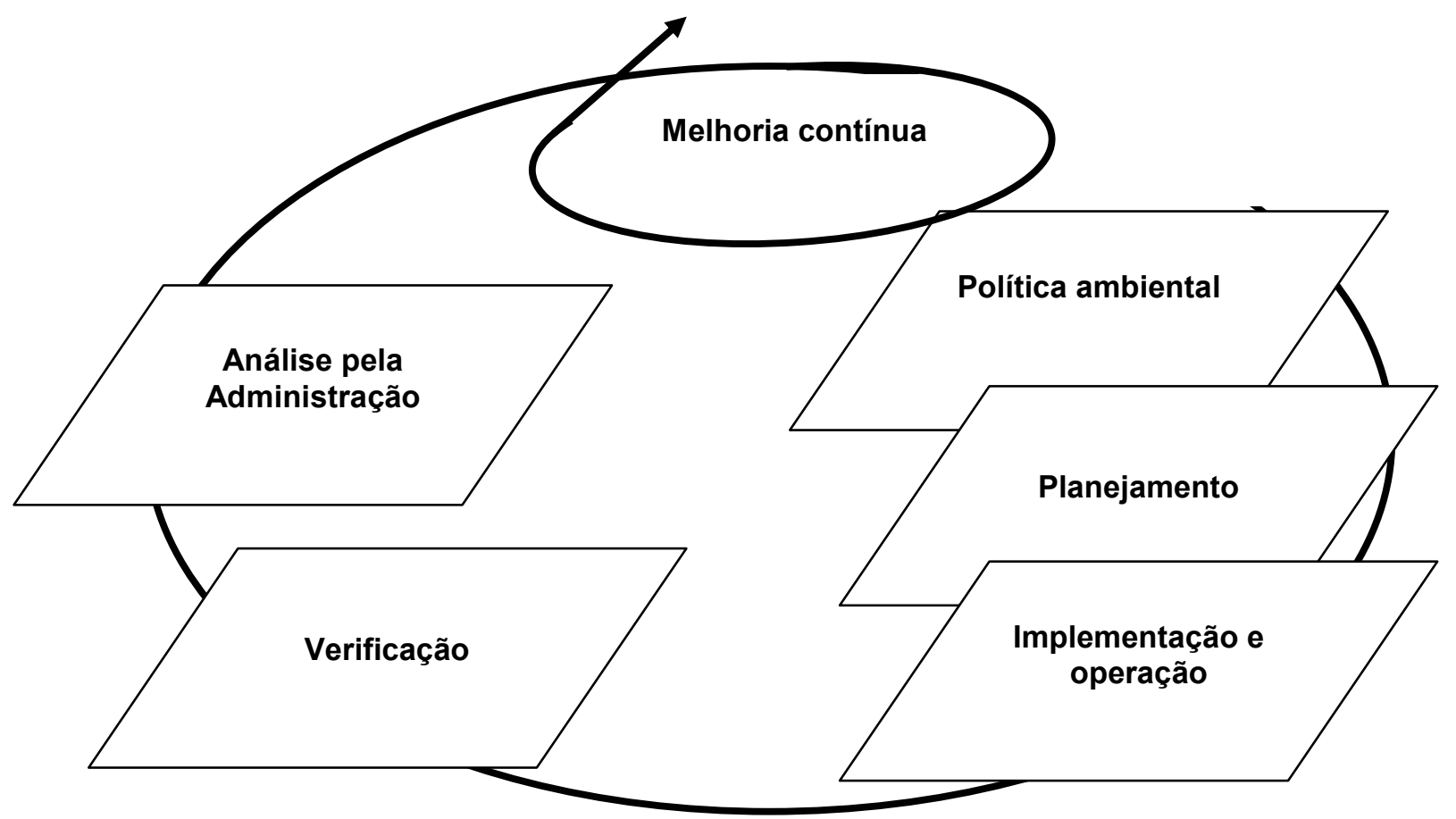

Figura 1- Modelo do Sistema de Gestão Ambiental para esta Norma Fonte: ABNT NBR ISO 14001:2004

De acordo com a NBR ISO 14001 (2004), a política ambiental é uma declaração da organização expondo suas intenções e seus princípios em relação a seu desempenho ambiental global, que provê uma estrutura para ação e definição de seus objetivos e suas metas ambientais. Para se criar uma política ambiental é necessária uma avaliação ambiental inicial, para assegurar que ela seja estabelecida com base no reconhecimento dos impactos ambientais que a empresa produz. Dessa 
forma é necessário definir o escopo do sistema de gestão ambiental da empresa.

O planejamento deve abranger os aspectos ambientais, os requisitos legais, os objetivos, metas e programas. Para isso são necessárias informações de aspectos ambientais de atividades, produtos e serviços, bem como os impactos significativos desses aspectos, além de requisitos legais (envolvendo nacionais, internacionais, estaduais, municipais e departamentais), requisitos financeiros, operacionais, comerciais, requisitos corporativos e opções tecnológicas.

Para implementação e operação, são necessárias informações de necessidades dos recursos humanos (como treinamento, competências, nível de experiência, habilidades, conscientização, conhecimento), aspectos e impactos ambientais associados às operações, informações sobre recursos financeiros, critérios operacionais, procedimentos, informações com relação a documentos (como declaração de política, objetivos e metas, normas internas e externas, procedimentos, aspectos ambientais entre outros) e informações com relação a situações de emergência, potenciais acidentes, ações para minimizar o dano ambiental, bem como lista de órgãos de atendimento e rotas de evacuação.

Na fase de verificação são necessárias informações de resultados de avalia- ções periódicas, resultados de auditorias, listas de não-conformidades e suas causas, resultados de registros de reclamações, resultados de ações corretivas e preventivas, registros de reuniões ambientais, de aspectos ambientais significativos, de treinamento, monitoramento de processos, incidentes, armazenamento, proteção, recuperação e descarte de registros.

Por fim, na fase da análise pela administração, são requisitadas informações sobre necessidade de alterações no sistema da gestão ambiental, oportunidades de melhoria, reclamações externas, desempenho ambiental da organização, bem como informações de situações de ações corretivas e preventivas.

No Quadro 1 estão identificadas as informações requeridas em cada uma das fases da norma NBR ISO 14001.

\section{A INFORMAÇÃO NOS ESTÁGIOS EVOLUTIVOS DA GESTÃO AMBIENTAL}

Numa economia baseada em recursos de informação, a concorrência entre as organizações baseia-se em sua capacidade de adquirir, tratar, interpretar e utilizar a informação de forma eficaz (MCGEE e PRUSAK, 1994).

Como a informação tem sido abordada com alta relevância em todos os níveis organizacionais, não poderia deixar de constar sua imprescindível relevância na 
variável ambiental. A turbulência ambiental aumenta a necessidade de não somente mais informações, mas de informações mais organizadas, compreensivas, precisas e atuais (KARAKE, 1997).

Companhias estão cada vez mais se perguntando como suprir mais e melhores informações com relação a como identificar e gerenciar riscos sociais, éticos e ambientais, e explicar como esses riscos podem ter importância a curto e longo prazo (WALKER, 2007).

É necessário considerar, portanto, que a integração da gestão ambiental nas distintas atividades requer e gera ao mes- mo tempo uma enorme quantidade de informações, das quais os profissionais têm necessidade para executar suas tarefas. Entretanto, as informações geradas em uma área de competência (por exemplo, na produção) podem ser de utilidade para os profissionais de outra área (na inovação, para o design de novos produtos ou processos, por exemplo; ou no marketing, para a promoção desses novos produtos etc). Para que não haja duplicação de esforços, as informações e os conhecimentos gerados não podem permanecer isolados dentro das áreas, mas circular entre elas, de modo a serem partilhados pelos profissionais na organização (CORAZZA, 2003).

Quadro 1 - Informações requeridas em cada um dos elementos integrantes da norma ISO 14001

\begin{tabular}{|c|c|}
\hline ELEMENTOS & INFORMAÇÕES \\
\hline $\begin{array}{l}\text { Política Ambi- } \\
\text { ental }\end{array}$ & $\begin{array}{l}\text { - Resultado de uma avaliação ambiental } \\
\text { - Escopo do sistema da gestão ambiental da empresa }\end{array}$ \\
\hline Planejamento & $\begin{array}{l}\text { - Aspectos ambientais de atividades, produtos e serviços } \\
\text { - Impactos sobre os aspectos ambientais } \\
\text { - Requisitos legais (nacionais, internacionais, estaduais, municipais, departamentais, } \\
\text { governo local) } \\
\text { - Outros requisitos (financeiros, operacionais, comerciais, acordos com autoridades } \\
\text { públicas, acordos com clientes, acordos com grupos comunitários ou organizações } \\
\text { não-governamentais, diretrizes de natureza não-regulamentar, requisitos de associ- } \\
\text { ações de classe, requisitos corporativos) } \\
\text { - Opções tecnológicas }\end{array}$ \\
\hline
\end{tabular}




\begin{tabular}{|c|c|}
\hline $\begin{array}{l}\text { Implementação } \\
\text { e Operação }\end{array}$ & $\begin{array}{l}\text { - Política, objetivos e metas } \\
\text { - Normas internas e externas } \\
\text { - } \text { Recursos humanos e habilidades especializadas } \\
\text { - Nível de conscientização, conhecimento, compreensão e habilidades dos emprega- } \\
\text { - Nos } \\
\text { - Recessidades de treinamento dos empregados } \\
\text { - Tecnologia } \\
\text { - } \text { Operações associados aos aspectos e impactos ambientais } \\
\text { - Locais de armazenagem de documentos } \\
\text { - Locais para distribuição dos documentos } \\
\text { - Procedimentos operacionais associados aos aspectos ambientais } \\
\text { - Critérios operacionais nos procedimentos } \\
\text { - Potenciais situações de emergência e potenciais acidentes } \\
\text { - Natureza dos perigos locais como líquidos inflamáveis, gases comprimidos etc. } \\
\text { - Lista de pessoas-chave e órgãos de atendimentos (corpo de bombeiros, hospitais) } \\
\text { - Rotas de evacuação e pontos de encontro } \\
\text { - Formas para minimizar o dano ambiental }\end{array}$ \\
\hline Verificação & $\begin{array}{l}\text { - } \text { Indicadores de desempenho } \\
\text { - Resultados de avaliações periódicas } \\
\text { - Não-conformidades, suas causas e ações para evitar sua repetição } \\
\text { - Resultados de ações corretivas e preventivas executadas } \\
\text { - } \text { Armazenamento, proteção, recuperação, retenção e descarte de registros } \\
\text { - Registro de reclamações, treinamento, monitoramento de processo, inspeção, ma- } \\
\text { nutenção e calibração, incidentes, requisitos legais, aspectos ambientais, reuniões } \\
\text { - } \text { ambientais, desempenho ambiental, conformidade legal } \\
\text { - Resultados de auditorias internas }\end{array}$ \\
\hline $\begin{array}{l}\text { Análise pela } \\
\text { Administração }\end{array}$ & $\begin{array}{l}\text { - Recomendações/oportunidades de melhoria } \\
\text { - } \text { Alterações na política, objetivos e metas ambientais } \\
\text { - } \text { Desempenho ambiental da organização } \\
\text { - } \text { Reclamações externas } \\
\text { - } \text { Resultados de auditorias internas } \\
\text { - } \quad \text { Situação das ações corretivas e preventivas }\end{array}$ \\
\hline
\end{tabular}

Fonte: Adaptado da NBR ISO 14001:2004

Alguns exemplos de informações utilizadas na gestão ambiental podem ser descritos por Corazza (2003), que são utilizados como indicadores ambientais para análise do desempenho ambiental. Alguns dizem respeito à qualidade do ar e da água, à quantidade de energia e de água consumidas, à geração e à disposição de resíduos (inclusive a possibilidade de reciclagem) e, ainda, à segurança no trabalho 
(condições de iluminação, ventilação, baruIho, poeira, calor, vibração, temperatura, odores, substâncias tóxicas etc).

No entanto, algumas dessas informações podem ser utilizadas tanto em estágios diferentes da evolução ambiental como se repetir em vários estágios, sendo, porém, utilizadas com grau de relevância diferente.
Dessa forma, na próxima seção apresenta-se um diagnóstico das tomadas de decisão, informações e agentes decisórios envolvidos nos estágios evolutivos da gestão ambiental segundo a abordagem de Jabbour e Santos (2006), que compreendem os estágios de especialização funcional, integração interna e integração externa, conforme Figura 2.

\begin{tabular}{|c|c|}
\hline & $\begin{array}{l}\text { Integração externa da dimensão ambiental } \\
\text { A gestão ambiental se estende a todas as áreas funcionais } \\
\text { A variável ambiental é considerada fonte geradora de vantagem } \\
\text { competitiva } \\
\text { É determinante da estratégia empresarial } \\
\text { Forte impacto nas decisões de cúpula }\end{array}$ \\
\hline & $\begin{array}{l}\text { Integração interna da dimensão ambiental } \\
\text { Importância da variável ambiental baseada em objetivos definidos } \\
\text { por outras áreas } \\
\text { A variável ambienta não impacta sobre todas as áreas funcionais } \\
\text { Apoio da função ambiental a projetos específicos de determinadas } \\
\text { divisões }\end{array}$ \\
\hline & $\begin{array}{l}\text { Especialização funcional da dimensão ambiental } \\
\text { Neutralidade estratégica } \\
\text { Prevenção de problemas ambientais para a consecução da estraté- } \\
\text { gia empresarial } \\
\text { Reação à legislação ambiental } \\
\text { Institucionalização de área responsável pelo meio ambiente } \\
\text { Desconsideração do potencial estratégico da variável ambiental }\end{array}$ \\
\hline
\end{tabular}

Figura 2 - A evolução da gestão ambiental nas organizações

Fonte: Jabbour e Santos (2006)

\subsection{Tomadas de Decisão e Informações Necessárias no Estágio de Especializa- ção Funcional}

Segundo Jabbour e Santos (2006), o estágio de especialização funcional da gestão ambiental compreende as principais similaridades dos seguintes níveis de ma- turidade da variável ambiental na empresa: abordagem reativa (MAIMON, 1994), padrão reativo (SANCHES, 2000), controle (ROHRICH e CUNHA, 2004), controle da poluição (BARBIERI, 2004), integração pontual (CORAZZA, 2003) e controle ambiental nas saídas. 
A fase inicial da gestão ambiental empresarial é de caráter corretivo, as exigências estabelecidas pela legislação ambiental são vistas como problemas a serem resolvidos pelos órgãos técnicos e operacionais da empresa sem autonomia decisória e esse trabalho é visto como um custo interno adicional. Do ponto de vista ambiental, as práticas de controle da poluição apresentam-se como soluções pobres por estarem focadas nos efeitos e não nas causas da poluição e alcançam poucos efeitos sobre o montante de recursos que a empresa utiliza (BARBIERI, 2004).

Barbieri (2004, p.104) afirma que nessa fase o objetivo é atender às exigências estabelecidas nos instrumentos de comando e controle às quais a empresa está sujeita e às pressões da comunidade. Corazza (2003) fixa, que por ser uma abordagem pontual, a organização reage às pressões da legislação ambiental. Segundo Maimon (1996), esse comportamento reativo das empresas é orientada para o atendimento das demandas mercadológicas e adequação à legislação ambiental vigente.

Outra informação importante nesse estágio é a permanência de poluentes na disposição final dos resíduos, pois se estes resíduos contiverem substâncias perigosas, a sua disposição final em condições seguras vai requerer autorização ao órgão ambiental. (BARBIERI, 2004 p.105).
Ainda nesse estágio, Barbieri (2004, p.105) enfatiza que são relevantes informações sobre normas, leis e custos de produção, pois o destino dos resíduos precisa ser licenciado pelo órgão ambiental e outras atividades administrativas e operacionais reguladas por lei.

Por ser uma configuração sensível às pressões sociais emergentes, a empresa tende a controlar a poluição e descarta a formulação de uma ecoestratégia (JABBOUR e SANTOS, 2006; DONAIRE, 1994).

\subsubsection{Agentes organizacionais envolvi- dos}

Nesse estágio é perceptível a particularidade que se apresenta a responsabilidade das questões ambientais conforme as características das organizações.

De acordo com Moreira (2001, p.52), a empresa que apresenta um nível mínimo de gestão ambiental geralmente possui um departamento de meio ambiente, responsável pelo atendimento às exigências do órgão ambiental e por indicar os equipamentos ou dispositivos de controle ambiental mais apropriados à realidade da empresa e ao potencial de impactos ambientais. Ou seja, a empresa demonstra quase sempre uma postura reativa, procurando evitar os riscos e limitando-se ao atendi- 
mento dos requisitos legais, o que normalmente significa investimentos.

Para Seiffert (2005), a gestão ambiental pode ser de incumbência, apenas, de alguns advogados ou engenheiros. Já para Corazza (2003), a especialização funcional é caracterizada pela criação da função, cargo e/ou departamento ambiental, recrutando especialistas em controle da poluição e adequação ambiental em manufatura (JABBOUR e SANTOS, 2006). Para Rohrich e Cunha (2004) a gestão ambiental tem forte envolvimento com produção/manufatura.

Algumas pesquisas norteamericanas constataram que é a média gerência que tem tomado as primeiras iniciativas quando a empresa se defronta com problemas ambientais, muitas vezes sem um apoio expresso por parte dos ní- veis mais altos. No entanto, nos casos em que a alta administração assume efetivamente um compromisso de melhoria da qualidade ambiental dos processos e produtos da empresa é que tais esforços são bem-sucedidos (SANCHES, 2000).

Para Donaire (1994, p.72) a cúpula administrativa entende que a variável ecológica é importante, que deve ser considerada na política organizacional, que há a necessidade de assessoria especializada, porém essa conscientização não se dissemina para os níveis hierárquicos mais baixos da empresa, restringindo-se apenas à alta administração.

O Quadro 2 apresenta uma síntese das decisões, informações e agentes decisórios no estágio evolutivo de especialização funcional.

Quadro 2 - Informações, decisões e agentes decisórios envolvidos no estágio evolutivo de especialização funcional da gestão ambiental

\begin{tabular}{|l|l|l|}
\hline \multicolumn{1}{|c|}{ Decisões a serem tomadas } & \multicolumn{1}{|c|}{ Informações sobre } & $\begin{array}{l}\text { Agentes organizacionais en- } \\
\text { volvidos }\end{array}$ \\
\hline - Controle da poluição & - Quantidade de Poluentes nos & - Advogados ou engenheiros \\
- Exigências do órgão ambiental & resíduos & - Função produção \\
- Exigências da comunidade & - Legislação e normas & - Alta administração \\
- Evitar riscos & - Pressões da comunidade & - Especialistas em controle da \\
- Adequação à legislação & - Demanda do mercado & poluição \\
- Disposição final de resíduos & & - Média gerência \\
\hline
\end{tabular}

4.2 Tomadas de Decisão e Informações Necessárias no Estágio de Integração Interna

De acordo com Jabbour e Santos (2006), o estágio de integração interna da gestão ambiental na empresa abrange os seguintes níveis de maturidade da variável ambiental: abordagem preventiva (MAIMON, 1994); padrão pró-ativo (SANCHES, 2000); prevenção (ROHRICH 
e CUNHA, 2004); integração preventiva (BARBIERI, 2004); integração pontual (CORAZZA, 2003) e controle nas práticas e processos industriais (DONAIRE, 1994).

Nessa fase, as soluções para os problemas ambientais são vistas como meios para aumentar a produtividade da empresa, sendo para isso necessário rever os produtos e processos para reduzir a poluição na fonte, reutilizar e reciclar o máximo de resíduos. Essa abordagem permite reduzir a poluição e o consumo de recursos para a mesma quantidade de bens e serviços produzida (BARBIERI, 2004).

Pelo fato deste estágio se preocupar basicamente com a prevenção da poluição (JABBOUR e SANTOS, 2006), o desempenho da gestão ambiental é baseado em legislações ou exigências do mercado, além de informações sobre redução dos custos com materiais e energia, economia na disposição final dos resíduos, redução dos passivos ambientais, melhora geral das condições de trabalho e da imagem da empresa (BARBIERI, 2004).

Donaire (1994) e Barbieri (2004) afirmam que são necessárias informações de tipos de materiais (seleção de matériasprimas), modos de conservação de energia (reaproveitamento), desenvolvimento de novos produtos e processo, formas de modificação de equipamentos, formas de reuso e reciclagem de resíduos, além da importância de se estabelecer planos de ma- nutenção preventiva e rever a gestão de estoques.

Barbieri (2004, p.108) propõe que para que a reciclagem seja feita externamente, os resíduos gerados precisam ser acondicionados e estocados em locais adequados até formar uma quantidade que compense seu transporte até o estabelecimento do reciclador.

Também é importante destacar que nesse estágio de prevenção, outras informações relevantes são as opiniões da comunidade, decisão de compra de consumidores e exigências a fornecedores (ROHRICH e CUNHA, 2004).

\subsubsection{Agentes organizacionais envolvi- dos}

Donaire (1994, p.72) esclarece que nessa fase ocorre a contratação de assessoria específica externa para lidar com a variável ambiental. Dessa forma, gerentes de linha são os mais engajados a lidar com as questões ambientais.

Para Rohrich e Cunha (2004), existe uma área de gestão ambiental formada por especialistas ambientais.

O desempenho da gestão ambiental é baseado em legislações ou exigências do mercado, segundo a interpretação da cúpula organizacional. Assim, cabe à gestão ambiental adequar o conteúdo de seus programas e políticas à estratégia dos ne- 
gócios vigentes (JABBOUR e SANTOS, 2006). Esses autores ainda frisam que a função ambiental não participa da formulação da estratégia, agindo, pois, segundo objetivos de prevenção de problemas ecológicos previamente estabelecidos e determinados.
O Quadro 3 apresenta uma síntese das decisões, informações e agentes decisórios no estágio evolutivo de integração interna.

Quadro 3 - Informações, decisões e agentes decisórios envolvidos no estágio evolutivo de integração interna da gestão ambiental

\begin{tabular}{|l|l|l|}
\hline \multicolumn{1}{|c|}{ Decisões a serem tomadas } & \multicolumn{1}{|c|}{ Informações sobre } & $\begin{array}{c}\text { Agentes organizacionais en- } \\
\text { volvidos }\end{array}$ \\
\hline - Mudanças de processos & - Tipos de materiais & - Assessoria ambiental exter- \\
- Mudanças de produtos & - Poluentes nos resíduos & - Gerentes de linha \\
- Decisões de compra dos con- & - Demanda do mercado & - Área de gestão ambiental, \\
sumidores & - Pressões da comunidade & tais \\
- Reaproveitamento de energia & - Condições de trabalho ambien- \\
- Reuso e reciclagem & - Imagem da empresa & - Alta administração \\
- Transporte de resíduos & - Planos de manutenção preventi- \\
- Exigências a fornecedores & va & \\
- Manutenção preventiva & - Legislação e normas & \\
\hline
\end{tabular}

4.3 Tomadas de Decisões e Informações Necessárias no Estágio de Integração Externa

Para Jabbour e Santos (2006), o estágio de integração externa da gestão ambiental, também chamado de integração estratégica da gestão ambiental, está alinhado aos seguintes estágios da gestão ambiental: integração matricial (CORAZZA, 2003), abordagem pró-ativa (MAIMON, 1994), padrão pró-ativo (SANCHES, 2000), estágio de controle ambiental na gestão administrativa (DONAIRE, 1994), próatividade (ROHRICH e CUNHA, 2004) e integração estratégica da variável ambiental (BARBIERI, 2004).
A principal característica desta etapa é a consideração das questões ambientais como questões estratégicas (BARBIERI, 2004). Assim, além das práticas de controle e prevenção da poluição, a empresa procura aproveitar oportunidades mercadológicas e neutralizar ameaças decorrentes de questões ambientais existentes ou que poderão ocorrer no futuro. Para tanto, as empresas analisam o processo de decisão de compra dos consumidores e as possíveis influências dos atributos ambientais (ROHRICH e CUNHA, 2004).

Com a extensão da gestão ambiental a todas as áreas funcionais (Jabbour e Santos, 2006), essas áreas são afetadas 
de forma diferenciada, em virtude de sua maior ou menor ligação funcional com a área ambiental (DONAIRE, 1999).

$\mathrm{Na}$ área de planejamento, Donaire (1999), Corazza (2003) e Barbieri (2004) ressaltam que deve ser avaliado o ambiente externo procurando identificar as oportunidades e os riscos existentes na legislação ambiental (normas nacionais e internacionais), no nível de consciência dos consumidores e da sociedade, no que está sendo feito pela indústria, no comportamento dos concorrentes e nos avanços tecnológicos. É ressaltado ainda que esta abordagem pro ativa envolve o gerenciamento do risco, a prevenção da poluição e a comunicação.

Nas atividades de marketing, Donaire (1999, p.100) e Corazza (2003) chamam a atenção para a necessidade de avaliação dos produtos atuais da organização (incluindo suas embalagens - uso excessivo, utilização de papéis não reciclados, tintas tóxicas etc), bem como a possibilidade de lançamento de produtos voltados ao "mercado verde". Atenção especial também deve ser dada à distribuição dos produtos, procurando idealizar eficientes sistemas de transporte e de reciclagem que levem em conta tanto os fatores econômicos como os ecológicos. Proporcionar serviços de assistência técnica e de orientação ao consumidor, assegurando que os produtos sejam usados e descartados de forma correta, é outra importante tarefa da área de marketing.

Junto à área de suprimentos, a área de meio ambiente pode iniciar seu trabalho pela análise da situação atual, coletando informações sobre a matéria-prima utilizada pela empresa e seus fornecedores, atentando para suas características ambientais, que deverão incluir: a escassez dos recursos, as implicações ambientais de sua extração e utilização, o grau de flexibilidade que o uso dos recursos substitutos pode oferecer, a facilidade de reaproveitamento e a reciclagem. A melhoria no sistema de armazenagem, a instalação de equipamentos mais modernos, a substituição das substâncias tóxicas e perigosas, os meios de transportes externos e internos, o treinamento adequado do pessoal para lidar com materiais perigosos e o número de manuseios do material em seus diferentes estágios desempenham papel importante da preocupação ambiental na área de suprimentos (DONAIRE, 1999, p.99).

Segundo Donaire (1999, p.94-97), a área de meio ambiente, junto à função produção deverá empenhar-se para que o processo produtivo, em todas suas fases, apresente menos consumo de energia, minimize a quantidade de resíduos, economize insumos, obedeça aos padrões de emissão e controle o fluxo de efluentes. Nesse sentido, deverá ser dada especial ênfase ao sistema de manutenção dos e- 
quipamentos e instalações que podem auxiliar de forma decisiva na melhoria dos padrões de qualidade ambiental, através da redução de incidência de falhas, melhora na eficiência das operações e economia dos insumos. Outra tarefa importante da produção é a administração de resíduos. Nesse sentido é importante identificar e conhecer o fluxo de resíduos, classificá-los segundo sua periculosidade e suas possibilidades de reaproveitamento e reciclagem, procurando eliminar ou reduzir a existência de resíduos na origem e desenvolvendo métodos seguros de transporte $\mathrm{e}$ descarte. É importante manter-se informado sobre o que está sendo feito por outras empresas e analisar a possibilidade de formar parcerias e associações com empresas para lidar de forma conjunta com esse problema. Concomitantemente deverão ser preparados planos de emergência específicos, com claras definições sobre procedimentos, responsabilidades, equipamentos e pessoal envolvido. Finalmente, devem ser estabelecidos normas e cronograma para a manutenção preventiva e auditoria sistemática das atividades sujeitas a acidentes de grande risco.

Para Donaire (1999, p.98), a área de meio ambiente deve estreitar seu relacionamento com a área de pesquisa e desenvolvimento (P\&D) para identificar dentre os produtos existentes quais poderiam ser melhorados dentro de um critério ambien- talmente responsável. Em seguida seriam feitas análises das fases do ciclo de vida dos produtos desde sua concepção, especificação, produção, uso, reutilização, descarte e deposição de resíduos, observando os impactos ambientais ocorridos em cada uma das fases, enfatizando a utilização de matérias-primas renováveis, tecnologia limpa, economia de insumos e energia e a possibilidade de reciclagem. Juntamente com a análise das diferentes fases do ciclo de vida do produto, podem ser incluídos outros tipos de análise, tais como de mercado e de valores.

Corazza (2003) afirma que nas atividades de inovação, seja de produtos ou de processos, não basta o produto ter apenas o seu desempenho ambiental melhorado, mas também apresentar melhorias em outros critérios, como: melhor desempenho técnico, melhor qualidade, mais segurança, redução de custos, melhor preço de revenda ou maior possibilidade de reaproveitamento e redução de custos para a sua disposição final. As inovações de processo ocorrem quando, ao lado da redução da poluição, levam à melhor produtividade dos recursos, a economia de materiais (devido à redução, substituição, reutilização ou reciclagem de insumos), a melhor utilização de subprodutos, a menor consumo de energia durante a produção, a redução de estoques de materiais, a conversão de resíduos em subprodutos com valor agrega- 
do e a redução de custos com disposição de resíduos e maior segurança no ambiente de trabalho.

A finalidade da área de relações públicas é estabelecer uma ligação permanente entre a empresa e o público em geral. Assim, a área ambiental deve participar da decisão de como a empresa utiliza a variável ecológica para reforçar sua imagem institucional ambiental, tanto junto à comunidade externa, em nível nacional ou internacional, como junto à comunidade interna, composta pelo pessoal que nela trabalha. Essa atitude permitirá o fornecimento adequado das informações sobre atividades da empresa em relação à questão ambiental, propiciando clareza e transparência em sua forma de atuação. Essa área deve programar visitas às fábricas, organizar mesas-redondas e informativos sobre o assunto, estabelecer ligações com os órgãos de controle, imprensa e grupos ambientalistas e propiciar programas de informações ambientais para os diferentes segmentos da comunidade (DONAIRE, 1999, p.101).

Um aspecto fundamental da área de recursos humanos está ligado ao treinamento para a gestão ambiental, desenvolvendo habilidades para lidar com essa questão. Nesse sentido, além da necessidade de prover informações de caráter específico relativas ao conhecimento da área ambiental, das ações tomadas e de seus reflexos na preservação do meio ambiente, reveste-se de maior importância a ênfase no treinamento que possibilite mudanças de atitude por parte dos gerentes e subordinados. Deve apoiar e auxiliar os gerentes em sua comunicação com seus subordinados, no sentido de enfatizar as questões ambientais, juntamente com os aspectos relacionados às economias de energia e de custos (DONAIRE, 1999, p.103).

Para Donaire (1999, p.106), a área ambiental deve trabalhar com o departamento de finanças para ajudar na avaliação financeira da questão ambiental. Assim, devem ser desenvolvidos esquemas especiais para avaliação de indicadores financeiros ambientais, que possam estabelecer índices para comparar as unidades produzidas com energia consumida, resíduos produzidos, materiais consumidos, água consumida etc., inclusão de externalidades, bem como o uso de recursos e investimentos ambientais que gozem de benefícios, tais como prazos mais longos, depreciação acelerada, abatimento nos impostos etc.

\subsubsection{Agentes organizacionais envolvi- dos}

Em estudos realizados em empresas norte-americanas de diversos setores, foi verificado que o departamento ambiental de empresas pro ativas é provido de pessoal com indivíduos determinados, mo- 
tivados, de alto nível, que têm um conceito de gestão ambiental que vai muito além da idéia de policiamento e da prevenção da poluição (SANCHES, 2000).

Para Jabbour e Santos (2006, p.445) a gestão ambiental se estende a todas as áreas funcionais, tendo forte impacto nas decisões da cúpula administrativa e sendo determinante da estratégia empresarial. A variável ecológica deixou de ser uma função exclusiva de produção para tornar-se também uma função da administração, envolvendo presidentes, diretores e corpo técnico específico. Nessa fase atinge um nível de maturação, que se caracteriza pela incorporação de sua avaliação nas atividades de linha da estrutura, notadamente na função produtiva e na administrativa (DONAIRE, 1994).

O papel da alta administração é fundamental para que as iniciativas e os es-

Quadro 4 - Informações, decisões e agentes decisórios envolvidos no estágio evolutivo de integração externa da gestão ambiental

\begin{tabular}{|c|c|c|}
\hline Decisões a serem tomadas & Informações sobre & $\begin{array}{c}\text { Agentes organizacionais en- } \\
\text { volvidos }\end{array}$ \\
\hline $\begin{array}{l}\text { - Exigências da sociedade } \\
\text { - Análise do mercado/decisão de } \\
\text { compra dos consumidores } \\
\text { - Neutralização de ameaças mer- } \\
\text { cadológicas } \\
\text { - Tecnologias } \\
\text { - Gerenciamento de riscos } \\
\text { - Prevenção da poluição } \\
\text { - Comunicação } \\
\text { - Preços dos produtos } \\
\text { - Sistemas de transporte } \\
\text { - Reaproveitamento e reciclagem } \\
\text { de materiais }\end{array}$ & $\begin{array}{l}\text { - Pressões da sociedade } \\
\text { - } \text { Demanda do mercado } \\
\text { - } \text { rentes } \\
\text { - Oportamento dos concor- } \\
\text { legislação ambiental } \\
\text { - Avanços tecnológicos } \\
\text { - Influências do governo } \\
\text { - Materiais tóxicos, papéis não } \\
\text { recicláveis } \\
\text { - Orientações ao consumidor } \\
\text { - Siso e descarte) } \\
\text { - Sistemas de transporte ecoló- }\end{array}$ & $\begin{array}{l}\text { - Departamento ambiental } \\
\text { - Especialistas ambientais de } \\
\text { alto nível } \\
\text { - Todas as áreas funcionais } \\
\text { envolvidas } \\
\text { - Alta administração }\end{array}$ \\
\hline
\end{tabular}




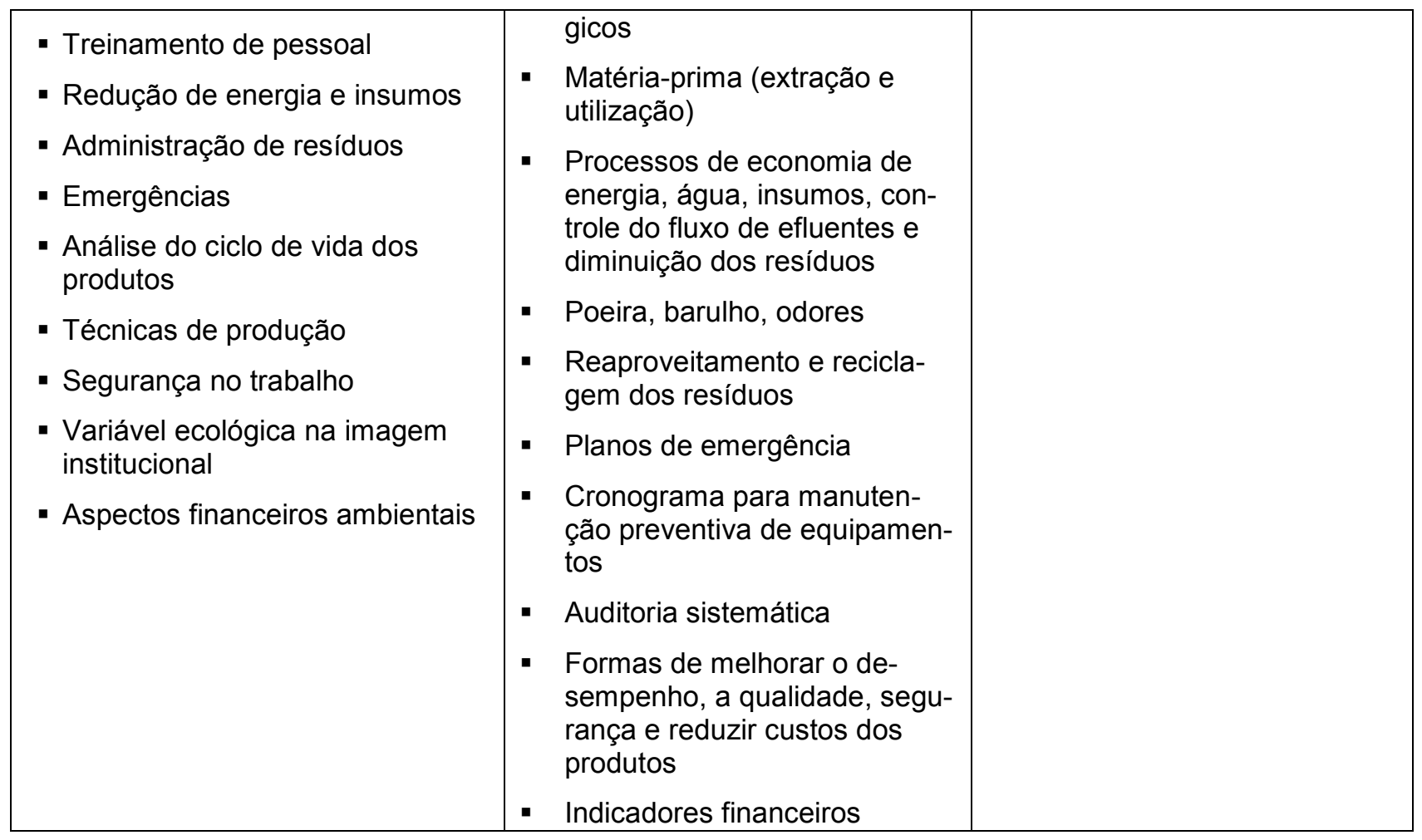

\section{CONSIDERAÇÕES FINAIS}

A revisão bibliográfica desenvolvida neste artigo demonstra que as organizações necessitam gerenciar a informação de forma tão peculiar quanto qualquer outro recurso empresarial. Dada a sua quantidade e diversidade, torna-se difícil gerenciá-la de maneira que os gestores a utilizem para a tomada de decisões.

As organizações, tanto aquelas que buscam sua conformidade ambiental como aquelas que zelam pela melhoria contínua do seu desempenho ambiental, se deparam com muitas informações, em quantidades, tipos e relevâncias diferentes, principalmente quando relacionadas aos estágios de evolução ambiental ao qual se encontram.
Dessa forma, foi possível identificar as tomadas de decisão, as informações e os agentes decisórios registrados pelos autores em cada um dos estágios evolutivos da gestão ambiental. Ressalta-se, entretanto, que essas informações podem ser ainda insuficientes, dada a complexidade da questão ambiental atribuída às organizações.

Confrontando as informações identificadas em cada um dos elementos componentes da NBR ISO $14001 \mathrm{com}$ as informações obtidas em cada um dos estágios evolutivos, pode-se concluir que para a organização atingir, no mínimo, sua conformidade ambiental, se faz necessária uma gestão da informação sistematizada com o grau de exigência da ISO 14001. 
Foi possível observar que as tomadas de decisão, a quantidade e os tipos de informação que são necessários em cada um dos estágios de evolução ambiental são diferenciados, porém com ressalva em alguns tipos, que podem ser utilizados em mais de um estágio. Assim pode-se concluir que existe uma tendência de sobreposição de estágios, onde características de um estágio posterior incorporam as do estágio anterior. Para tanto, se faz necessária uma gestão da informação de forma completa, considerando vários tipos e fontes de informação, para que estas possam auxiliar os dirigentes das organizações na sua formulação de estratégias e principalmente nas tomadas de decisão, adotando uma gestão pro ativa principalmente nas questões ambientais. Entretanto, vale lembrar que a relevância e o tipo das informações também podem variar de acordo com o tamanho, tipo e perspectivas estratégicas das organizações. Dessa forma, estudos teóricos e empíricos devem ser ainda realizados a fim de melhor compreender a gestão da informação nesses estágios de evolução da gestão ambiental, construindo assim uma forma estruturada para que as empresas e seus dirigentes possam planejar suas atividades futuras.

\section{REFERÊNCIAS}

ASSOCIAÇÃO BRASILEIRA DE NORMAS TÉCNICAS. NBR ISO 14001. Sistemas da gestão ambiental - requisitos com orienta- ções para uso. 2.ed. Rio de Janeiro: ABNT, 2004.

BARBIERI, J. C. Gestão ambiental empresarial: conceitos, modelos e instrumentos. São Paulo: Saraiva, 2004.

CORAZZA, R. I. Gestão ambiental e mudanças da estrutura organizacional. Revista de Administração de Empresas (RAEeletrônica). São Paulo, v. 2., n. 2, p. 1-23, Jul./Dez. 2003.

DONAIRE, D. Considerações sobre a influência da variável ambiental na empresa. Revista de Administração de Empresas (RAE), São Paulo, v. 34, n. 2, p. 68-77, Mar./Abr. 1994.

DONAIRE, D. Gestão ambiental na empresa. 2.ed. São Paulo: Atlas, 1999.

JABBOUR, C.J.C.; SANTOS, F.C.A. Evolução da gestão ambiental na empresa: uma taxonomia integrada à gestão da produção e de recursos humanos. Gestão \& Produção, v. 13, n.3, p. 435-448, Set./Dez. 2006.

KARAKE, Z. A. Managing information resources and environmental turbulence. Information Management \& Computer Security, v. 5, n. 3, p. 93-99, 1997.

MAIMON, D. Eco-estratégia nas empresas brasileiras: realidade ou discurso? Revista de Administração de Empresas (RAE), São Paulo, v. 34, n. 4, p. 119-130, 1994.

MAIMON, D. Passaporte verde: gestão ambiental e competitividade. Rio de Janeiro: Qualitymark, 1996.

McGEE, J. V.; PRUSAK, L. Gerenciamento Estratégico da informação: aumente a competitividade e a eficiência de sua empresa utilizando a informação como uma ferramenta estratégica. Rio de Janeiro: Campus, 1994.

MOREIRA, M. S. Estratégia e implantação de sistema de gestão ambiental modelo 
ISO 14000. Belo Horizonte: Editora de Desenvolvimento Gerencial, 2001.

ROHRICH, S. S.; CUNHA, J.C. A proposição de uma taxonomia para a análise da gestão ambiental no Brasil. Revista de Administração Contemporânea, v. 8, n. 4, p. 86-95, Out./Dez. 2004.

SANCHES, C. S. Gestão ambiental proativa. Revista de Administração de Empresas (RAE), São Paulo, v. 40, n. 1, p. 76-87, Jan./Mar. 2000.

SEIFFERT, M.E.B. ISO 14001: Sistemas de gestão ambiental. São Paulo: Atlas, 2005.

WALKER, David et. al. Environmental management systems: Information management and corporate responsibility. Journal of Facilities Management, v. 5, n. 1, p. 49-61, 2007.

Rosana Cristina Colombo Dionysio

Tecnóloga em Processamento de Dados (FATEC). Mestranda em Engenharia de Produção (EESC-USP) roancolombo@yahoo.com.br

Fernando César Almada Santos Professor do Departamento de Engenharia de Produção (EESC-USP). Engenheiro de Produção Mecânica (EESC-USP). Mestre em Administração (PUC-SP). Doutor em Administração de Empresas (FGV-SP) almada@sc.usp.br

\section{Title}

Evolution of the information which supports environmental management: an analysis centered on its evolution stages and decision agents

\section{Abstract}

The environmental issues that are being presented to the actual society invite governmental entities, companies and the population in general to use their initiative and also to apply solutions in order to reduce or prevent environmental problems. In this way, the aim of this article is to identify different types of decision, information and decision agents that are crucial for the company management of environmental issues, in spite of the evolution stage that these companies have achieved. Thus, a revision of literature on information management, environmental management and evolution stages was carried out. It was noticed that the types and amounts of information needed in each evolution of the environmental management are different. However, some types of information can be used in more than one stage of the process because of its particularities. In this sense, a complete information management process is necessary, including the various types and information sources which can support the company's leaders to define strategies and in the decision making, based on a proactive environmental management.

\section{Keywords}

Information management; Environmental management; ISO 14001 standard.

\section{Título}

La evolución de la información que apoya la gestión ambiental: un análisis centrado en los niveles evolutivos y en los agentes decisorios

\section{Resumen}

Delante de la cuestión ambiental explicitada fuertemente, gobierno, empresas y la población en general están siendo llamados a reflexionar, tomar iniciativas y aplicar soluciones en busca de una disminución o prevención de los problemas ambientales. En este contexto, el presente artículo tiene como objetivo identificar tipos de decisión, informaciones y agentes de- 
cisorios para la conducción de una administración de las cuestiones ambientales en las organizaciones, sea cual sea el nivel de evolución en el cual la empresa se encuentra. De esa forma, fue realizada una revisión bibliográfica con los temas gestión de la información, gestión ambiental y niveles evolutivos de la gestión ambiental. Fue posible observar que la cantidad y los tipos de información que son necesarios en cada uno de los niveles de la gestión ambiental son diferenciados, pero con salvedad en algunos tipos, que pueden ser utilizados en más de un nivel. Por lo tanto, se hace necesaria una gestión de la información de forma completa, considerando varios tipos y fuentes de información, para que éstas puedan auxiliar los dirigentes de las organizaciones en la formulación de estrategias y principalmente en las tomadas de decisión, adoptando una gestión ambiental proactiva.

\section{Palabras Clave}

Gestión de la información; Gestión ambiental; Norma ISO 14001.

Recebido em: 13.09.2007

Aceito em: 18.10.2007 